\title{
Synergies are a reason to prefer first-price auctions!
}

Citation for published version (APA):

Leufkens, K., \& Peeters, R. J. A. P. (2006). Synergies are a reason to prefer first-price auctions!

METEOR, Maastricht University School of Business and Economics. METEOR Research Memorandum No. 034 https://doi.org/10.26481/umamet.2006034

Document status and date:

Published: 01/01/2006

DOI:

10.26481/umamet.2006034

Document Version:

Publisher's PDF, also known as Version of record

\section{Please check the document version of this publication:}

- A submitted manuscript is the version of the article upon submission and before peer-review. There can be important differences between the submitted version and the official published version of record.

People interested in the research are advised to contact the author for the final version of the publication, or visit the DOI to the publisher's website.

- The final author version and the galley proof are versions of the publication after peer review.

- The final published version features the final layout of the paper including the volume, issue and page numbers.

Link to publication

\footnotetext{
General rights rights.

- You may freely distribute the URL identifying the publication in the public portal. please follow below link for the End User Agreement:

www.umlib.nl/taverne-license

Take down policy

If you believe that this document breaches copyright please contact us at:

repository@maastrichtuniversity.nl

providing details and we will investigate your claim.
}

Copyright and moral rights for the publications made accessible in the public portal are retained by the authors and/or other copyright owners and it is a condition of accessing publications that users recognise and abide by the legal requirements associated with these

- Users may download and print one copy of any publication from the public portal for the purpose of private study or research.

- You may not further distribute the material or use it for any profit-making activity or commercial gain

If the publication is distributed under the terms of Article $25 \mathrm{fa}$ of the Dutch Copyright Act, indicated by the "Taverne" license above, 
Kasper Leufkens, Ronald Peeters

Synergies are a reason to prefer first-price auctions!

$\mathrm{RM} / 06 / 034$

JEL code: D44, H57

\section{METE@R}

Maastricht research school of Economics of TEchnology and ORganizations

Universiteit Maastricht

Faculty of Economics and Business Administration P.O. Box 616

NL - 6200 MD Maastricht

phone : ++31433883830

fax $\quad:++31433884873$ 



\title{
Synergies are a reason to prefer first-price auctions!*
}

\author{
Kasper Leufkens $^{\dagger} \quad$ Ronald Peeters ${ }^{\dagger}$
}

September 1, 2006

\begin{abstract}
In this paper we show that in a private value setting first-price auctions can be preferred to second-price auctions. We consider a sequential auction of two objects with positive synergies and compare both auction formats. Although the second-price auction performs better in terms of efficiency and revenue, the first-price auction performs much better on a so far neglected dimension. Namely, the probability that the winner of the first object goes bankrupt is almost always higher when using the second-price rule. Our findings therefore support the common use of first-price auctions, most notably for procurement.
\end{abstract}

JEL Classification Codes: D44 (Auctions), H57 (Procurement).

Keywords: Auction, Bankruptcy, Synergies, Procurement.

\section{Introduction}

In private value settings second-price sealed-bid auctions are generally preferred to first-price sealed-bid auctions due to the desirable properties they have. First of all, the dominant bidding strategy is truth-revealing and therefore does not require any information on the situation or intention of competitors. Second, in equilibrium the auction is always guaranteed to be efficient. Besides, the revenue-equivalence theorem (Myerson, 1981) shows that the expected revenues from both auction formats are identical under certain assumptions.

Still, second-price auctions are hardly observed in practice and several theoretical explanations have been given for this. Rothkopf et al. (1990) argue that bidders might be reluctant to reveal their true valuation, since this can have negative implications for future auctions. Both in one-shot and repeated settings, collusion among bidders is less stable in first-price auctions than in second-price auctions (see for instance Robinson (1985), Fehl and Güth (1987), and Skrzypacz and Hopenhayn (2004)). Finally, when bidders are risk-averse or when their valuations are asymmetrically distributed, the revenue-equivalence theorem does not hold anymore. Holt (1980) shows that when bidders are risk-averse the first-price auction generates higher revenues since bidders then shade their bids less. When the valuation

\footnotetext{
${ }^{*}$ We would like to thank conference participants of EARIE 2006 for comments and suggestions.

${ }^{\dagger}$ Department of Economics, Maastricht University, P.O. Box 616, 6200 MD Maastricht, The Netherlands. Email: \{K.Leufkens, R.Peeters\}@algec.unimaas.nl. The second author is financially supported by the Dutch Science Foundation (NWO).
} 
distribution of one type of bidders stochastically dominates that of the other type of bidders, Maskin and Riley (2000) show that a first-price auction generates more revenue than a second-price. However in such a situation the first-price auction is not efficient anymore.

This paper also discusses asymmetries between the valuation distributions of two bidders but here the asymmetry is not exogenously given. We analyze a sequential auction of two objects in which positive synergies are present and compare the first- and second-price format. We find that both the efficiency and total revenue are then higher for the second-price auction. However, we also observe that bidders are more likely to receive a negative payoff under this auction format, which induces a higher probability on bankruptcy.

Many auction settings can be characterized as being sequential in nature and synergies are often present in such settings. The theoretical literature on sequential auctions with synergies only focusses on price trends. Branco (1997) shows that in a sequential auction of homogeneous objects a decreasing price trend, better known as the declining price anomaly, can be explained by the presence of positive synergies. Jeitschko and Wolfstetter (2002) extent this result to sequential auctions of stochastically equivalent objects. Leufkens et al. (2006) are the first to not only consider price trends and revenues, but also the consequences for bidders. In standard private value auctions it is not very interesting to analyze the consequences for bidders since they will never make losses. However, in presence of positive synergies this is not guaranteed anymore since auction participants bid above their valuations. Negative payoffs can lead to bankruptcy, particularly for auctions where potential synergies are high, which has disastrous effects on welfare. Especially for procurement auctions this is important, since governments are not only interested in revenues but also the social consequences.

\section{The model}

We consider a private value auction of two objects. The objects are auctioned sequentially and the auction rules are identical in both auctions. ${ }^{1}$ Two risk-neutral bidders participate in both auctions and for each object their valuation is uniformly distributed between 0 and 1 . Valuations are individually uncorrelated and drawn independently according to this distribution. Furthermore, the valuation for the second object is not known during the auction of the first object. After each auction bidders are informed whether or not they won the object. The bid and valuation in auction $k$ of bidder $i$ are denoted by $b_{k i}$ and $v_{k i}$. We incorporate the presence of positive synergies by multiplying the second auction valuation with a factor $s>1$ if the first auction is won. Although the valuation for the second object is not known during the first auction, bidders know that winning the first object increases this valuation from $v_{2 i}$ to $s v_{2 i}$ and thus increases their expected payoff of the second auction.

Our setting represents a recurring auction like the annual auctioning of contracts for

\footnotetext{
${ }^{1}$ Although most applications are in procurement settings, we follow the convention and analyze 'highest bid wins' auctions for expositional ease and without loss of generality.
} 
public services. The exact details of future contracts are not specified yet and therefore contracts are considered as a priori identical. Attributing the benefits from synergies only to the second object makes sense considering the order in which projects are executed. For instance, expertise is created during the first project and this gives benefits for the second, or specialized equipment is needed which then does not need to be acquired for a possible second project. Although we stress here the procurement setting for public contracts explicitly, the setting may find its application in other situations such as spectrum auctions where bidders benefit from a win in one area in the creation of a domain consisting of multiple contiguous areas.

Jeitschko and Wolfstetter (2002) and Tang Sørensen (2006) consider similar settings. Tang Sørensen (2006) only discusses a second-price sealed-bid auction and models positive synergies as a constant that is added to the value of the second object. A weakness in this approach is that the marginal synergy is infinite if the valuation is close to zero (see Menezes and Monteiro (2004)). In Jeitschko and Wolfstetter (2002) benefitting from positive synergies means that the valuation is uniformly distributed on $[0,2]$ instead of $[0,1]$. Our way of modeling synergies ensures there is an observable relationship between the benefits from synergies and the intrinsic value of the second object. In both aforementioned articles the focus is only on revenues and price trends whereas we are interested in the wider (social) consequences the presence of positive synergies has.

\section{$3 \quad$ First-price sealed-bid}

Theorem 1 For a sequential first-price sealed-bid auction with independent, individually uncorrelated valuations, two risk-neutral bidders, two objects and a synergy factor $s>1$, the bidding strategies given by

$$
b_{1 i}^{*}\left(v_{1 i}\right)=\frac{1}{2} v_{1 i}+\Delta \quad \text { with } \quad \Delta=\frac{s^{2}}{s^{2}-1}\left\{\frac{1}{2} s-1-\frac{1}{s}+\frac{1}{2} \frac{1}{s^{2}}+\frac{1}{2} \frac{\operatorname{arcsinh}\left(\sqrt{s^{2}-1}\right)+\arcsin \left(\frac{1}{s} \sqrt{s^{2}-1}\right)}{\sqrt{s^{2}-1}}\right\}
$$

and

$$
b_{2 i}^{*}\left(v_{2 i}\right)= \begin{cases}\frac{v_{2 i}}{1+\sqrt{1-\left(1-\frac{1}{s^{2}}\right) v_{2 i}^{2}}} & \text { if auction } 1 \text { is lost } \\ \frac{s v_{2 i}}{1+\sqrt{1+\left(1-\frac{1}{s^{2}}\right)\left(s v_{2 i}\right)^{2}}} & \text { if auction } 1 \text { is won }\end{cases}
$$

constitute a unique symmetric equilibrium.

Proof. See appendix.

The factor $\Delta$ in the theorem is the option value effect of winning the first auction. This option value is precisely the difference in expected instantaneous payoffs for the second auction, before knowing the second auction valuation, between winning and losing. In line with intuition, the option value effect is increasing in the synergy factor. 
If the option value $\Delta$ exceeds half of the valuation for the first object, bidders bid above their private valuation and as a consequence the winner of the first auction can make a negative first auction instantaneous payoff. For values of the synergy factor above 1.8179 (when $\Delta>\frac{1}{3}$ ), the expected first auction instantaneous payoff is negative. For synergy factors even above 2.2113 (when $\Delta>\frac{1}{2}$ ), bidders are guaranteed to make a loss in the first auction.

Losses that are made in the first auction can, but are not guaranteed to, be recovered in the second auction. In case the first auction winner is not able to recover its loss in the second auction, bankruptcy results. Figure 1 displays the probability that bankruptcy occurs in the first-price sealed-bid sequential auction with positive synergies as a function of the synergy factor.

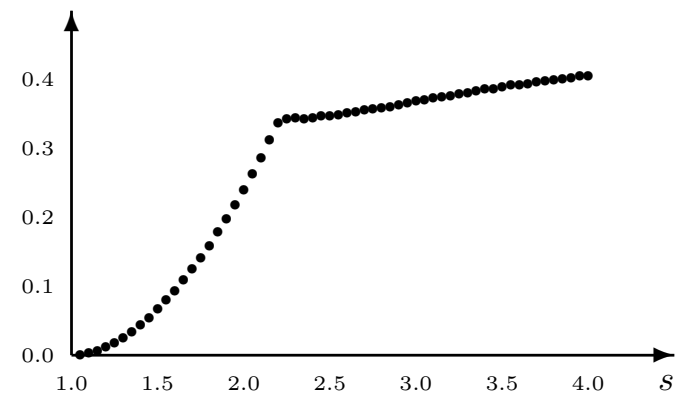

Figure 1: The probability of bankruptcy as a function of $s$.

The presence of synergies causes the second auction to be asymmetric. Asymmetric first-price sealed-bid auctions are known to possess inefficiencies even if bidders have the same attitude towards risk. The second-price counterpart never possesses such inefficiencies, regardless of asymmetries and differences in attitudes towards risk. As a consequence, in addition to possible ex post inefficiencies due to absence of hindsight in future valuations, even ex ante inefficiencies can be observed. To be more specific, the inefficiency that can occur is that the loser of the first auction can win the second auction although that the synergy-adjusted value of the first auction winner is higher.

\section{Second-price sealed-bid}

Theorem 2 For a sequential second-price sealed-bid auction with independent, individually uncorrelated valuations, two risk-neutral bidders, two objects and a synergy factor $s>1$, the bidding strategies given by

$$
b_{1 i}^{*}\left(v_{1 i}\right)=v_{1 i}+\Delta \quad \text { with } \quad \Delta=\frac{1}{2} s-\frac{1}{2}
$$

and

$$
b_{2 i}^{*}\left(v_{2 i}\right)= \begin{cases}v_{2 i} & \text { if auction } 1 \text { is lost } \\ s v_{2 i} & \text { if auction } 1 \text { is won }\end{cases}
$$


constitute a unique symmetric linear equilibrium in weakly dominant strategies.

Proof. See Leufkens et al. (2006).

As in the previous section, the factor $\Delta$ represents the option value effect of winning the first auction and equals the difference in expected instantaneous payoffs for the second auction between winning and losing the first auction before the second auction valuation is known. Also here the option value effect is increasing in the synergy factor.

Bidders always overbid due to the fact that $\Delta$ is positive. This does not imply that the first auction winner makes a loss in the first auction, since the price is determined by the losing bidder. Nevertheless, losses can be made. An instantaneous loss is guaranteed if the auction is won and the option value $\Delta$ exceeds the private valuation. For synergy factors exceeding 1.6667 (when $\Delta>\frac{1}{3}$ ) the expected first auction instantaneous payoff is negative and for synergy factors larger than 3 (when $\Delta>1$ ) instantaneous losses are always made.

Again, losses that are made in the first auction can, but are not guaranteed to, be recovered in the second auction and bankruptcy problems can be observed. Figure 2 displays the probability that bankruptcy occurs in the second-price sealed-bid sequential auction with positive synergies as a function of the synergy factor.

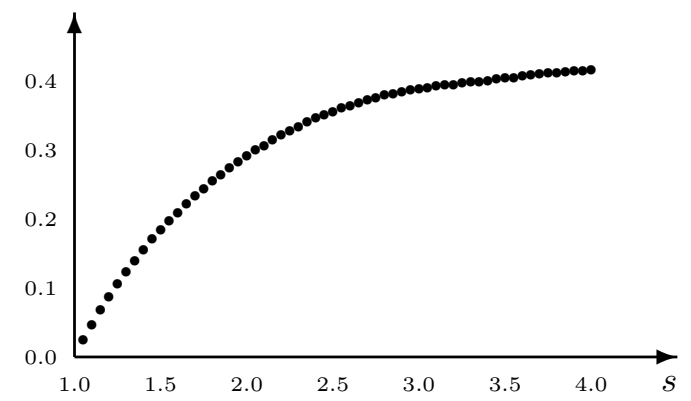

Figure 2: The probability on bankruptcy as a function of $s$.

As already mentioned, in contrast to the first-price counterpart, ex ante efficiencies are guaranteed not to occur here. Ex post inefficiencies due to the lack of perfect foresight concerning future valuations are still possible.

\section{A Comparison between both formats}

In Figure 3 the difference in bankruptcy probabilities between the second-price auction and the first-price auction is displayed for different values for the synergy factor. The values in this figure are found by subtracting the value in Figure 1 from the value in Figure 2 for each $s$. We see that for almost all values of $s$ the difference is positive, meaning that for almost all synergy factors bankruptcy is more likely to occur in the second-price auction than in the first-price auction. 


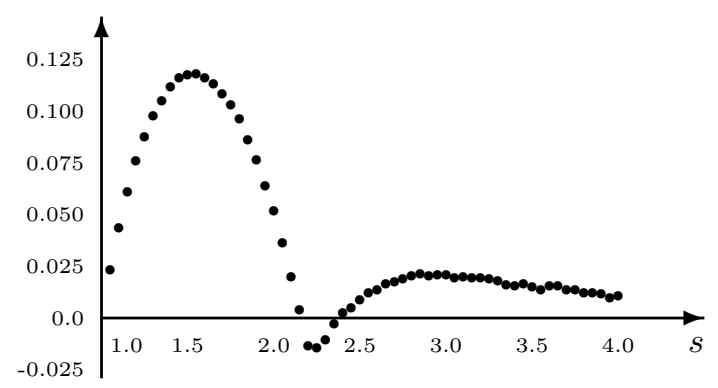

Figure 3: Difference in bankruptcy probability between the two formats.

Figure 4 displays the difference in the likelihood by which inefficiencies occur between the firstprice auction and the second-price auction format. Owing to the efficiency of the second-price auction, the difference is precisely the likelihood by which the first-price auction is inefficient. We see that the probability on an inefficient outcome is bounded from above by $8.6 \%$.

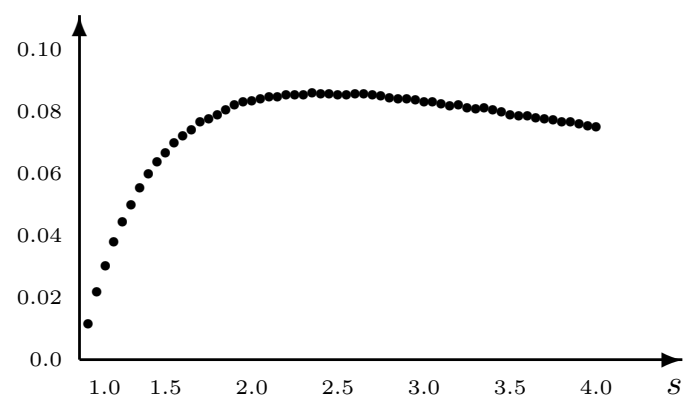

Figure 4: Difference in the probability on inefficiency between the two formats.

From the two figures above we can conclude that for only a small region of the synergy factor the second-price auction performs better on both efficiency and bankruptcy. For all remaining values of the synergy factor the first-price auction performs better regarding bankruptcy but is outperformed by the second-price auction regarding efficiency.

The smaller probability on bankruptcy in a first-price auction is a consequence of the inefficiency in the second auction. The only kind of inefficiency that can occur in the second auction of the first-price auction is that the loser of the first auction wins even though the (synergy adjusted) valuation of the first auction's winner is higher. This inefficiency has a negative impact on the option value effect of winning the first auction. In a second-price auction this inefficiency does not exist and consequently the factor $\Delta$ is always larger than for a first-price auction (see Güth et al. (2005)). Hence in the first-price auction the bidding competition will be less fierce in the first auction and consequently decreases the probability on bankruptcy.

As predicted by Maskin and Riley (2000), the expected revenue from the second auction is higher for the first-price auction. The expected revenue from the first auction is higher for the second-price auction since the factor $\Delta$ is always larger. The total revenue from both 
auctions is larger for the second-price auction but can be shown to be never more than $4 \%$ above that from the first-price auction.

\section{Conclusion}

In our sequential auction with synergies second-price sealed-bid auctions are always efficient whereas first-price sealed-bid auctions are not. Also, the total revenue from the second-price auction is higher. Still, a first-price auction can be preferred since the probability that the winner of the first object goes bankruptcy is almost always smaller. In theory second-price auctions are generally preferred for private value settings and we have shown that when complementarities are present this should not necessarily be the case. Our findings support the common use of first-price auctions, most notably for procurement settings.

For the second-price format the analysis can be extended to $n \geq 2$ bidders and a general cumulative distribution function for the valuations (see Leufkens et al. (2006)). For the first-price format we need to assume a cumulative distribution function to get a closed-form solution for the equilibrium bidding strategies. A closed-from solution for the equilibrium bidding strategy for an asymmetric first-price auction with more than two bidders has not been found so far. Therefore we are not able to extend the comparison to more than two bidders or a general distribution function.

\section{References}

1. Branco F. (1997). Sequential auctions with synergies: An example. Economics Letters, 54 (2), 159-163.

2. Fehl, U. and W. Güth (1987). Internal and external stability of bidder cartels in auctions and public tenders. International Journal of Industrial Organization, 5 (3), 303-313.

3. Güth, W., R. Ivanova-Stenzel, and E. Wolfstetter (2005). Bidding behavior in asymmetric auctions: An experimental study. European Economic Review, 49 (7), 1891-1913.

4. Holt, C. (1980). Competitive bidding for contracts under alternative auction procedures. Journal of Political Economy, 88 (3), 433-445.

5. Jeitschko, T.D. and E. Wolfstetter (2002). Scale economies and the dynamics of recurring auctions. Economic Inquiry, 40 (3), 403-414.

6. Leufkens, K., R. Peeters, and D. Vermeulen (2006). Sequential auctions with synergies: The paradox of positive synergies. Meteor Research Memorandum 06/018, Universiteit Maastricht, The Netherlands.

7. Maskin, E. and J. Riley (2000). Asymmetric auctions. Review of Economic Studies, 67 (3), 413-438. 
8. Menezes, F. and P. Monteiro (2004). Auctions with synergies and asymmetric buyers. Economics Letters, 85 (2), 287-294.

9. Myerson, R.B. (1981). Optimal auction design. Mathematics of Operation Research, 6 (1), 58-73

10. Plum, M. (1992). Characterization and computation of Nash-equilibria for auctions with incomplete Information. International Journal of Game Theory, 20 (4), 393-418.

11. Robinson, M.S. (1985). Collusion and the choice of auction. RAND Journal of Economics, 16 (1), 141-145.

12. Rothkopf, M.H., T.J.Teisberg, and E.P. Kahn (1990). Why are Vickrey auctions rare? Journal of Political Economics, 98 (1), 94-109.

13. Skrzypacz, A. and H. Hopenhayn (2004). Tacit collusion in repeated auction. Journal of Economic Theory, 114 (1), 153-169.

14. Tang Sørensen, S. (2006). Sequential auctions for stochastically equivalent complementary objects. Economics Letters, 91 (3), 337-342.

\section{Appendix}

The expected instantaneous payoff of auction 1 for bidder $i$ prior to the realization of the valuations for this auction is denoted by $\bar{\pi}_{1 i}$. The expected instantaneous payoff of auction 2 for bidder $i, \bar{\pi}_{2 i}$, is prior to the realization of the valuations for this auction but given the outcome of the first auction. The winner and loser of the first auction are referred to as respectively bidder $w$ and $\ell$ in the second auction.

\section{Proof to Theorem 1}

1. Second auction bid functions. The bid functions follow directly from Plum (1992).

2. The factor $\Delta$. Note that both second auction bid functions are strictly increasing functions

on $[0,1]$ with minimum value 0 and maximum value $\frac{s}{s+1}$. The first auction winner's bid coincides with the first auction loser's bid if and only if

$$
b_{w}^{*}\left(v_{w}\right)=b_{\ell}^{*}\left(v_{\ell}\right) \quad \Longleftrightarrow \quad v_{w}=\frac{1}{s} \frac{v_{\ell}}{\sqrt{1-\left(1-\frac{1}{s^{2}}\right) v_{\ell}^{2}}} \quad \text { or } \quad v_{\ell}=\frac{s v_{w}}{\sqrt{1+\left(1-\frac{1}{s^{2}}\right)\left(s v_{w}\right)^{2}}}
$$

Therefore, in equilibrium, the expected instantaneous payoffs for the second auction after having learned the second auction valuation are

$$
\bar{\pi}_{w}^{*}\left(v_{w}\right)=\left(s v_{w}-b_{w}^{*}\left(v_{w}\right)\right) \cdot \operatorname{Pr}\left\{b_{w}^{*}\left(v_{w}\right) \geq b_{\ell}^{*}\left(v_{\ell}\right)\right\}=\frac{\left(s v_{w}\right)^{2}}{1+\sqrt{1+\left(1-\frac{1}{s^{2}}\right)\left(s v_{w}\right)^{2}}}
$$


for the first auction winner, and

$$
\bar{\pi}_{\ell}^{*}\left(v_{\ell}\right)=\left(v_{\ell}-b_{\ell}^{*}\left(v_{\ell}\right)\right) \cdot \operatorname{Pr}\left\{b_{\ell}^{*}\left(v_{\ell}\right) \geq b_{w}^{*}\left(v_{w}\right)\right\}=\frac{v_{\ell}^{2}}{1+\sqrt{1-\left(1-\frac{1}{s^{2}}\right) v_{\ell}^{2}}} \frac{1}{s}
$$

for the first auction loser. Hence, the expected instantaneous payoffs for the second auction before knowing the second auction valuation are

$$
\begin{aligned}
& \bar{\pi}_{w}^{*}=\int_{0}^{1} \bar{\pi}_{w}^{*}\left(v_{w}\right) \mathrm{d} v_{w}=\int_{0}^{1} \frac{\left(s v_{w}\right)^{2}}{1+\sqrt{1+\left(1-\frac{1}{s^{2}}\right)\left(s v_{w}\right)^{2}}} \mathrm{~d} v_{w} \stackrel{3}{=} \int_{0}^{1} \frac{\left(s v_{w}\right)^{2}\left[1-\sqrt{1+\left(1-\frac{1}{s^{2}}\right)\left(s v_{w}\right)^{2}}\right]}{1-\left(1+\left(1-\frac{1}{s^{2}}\right)\left(s v_{w}\right)^{2}\right)} \mathrm{d} v_{w} \\
& =\int_{0}^{1} \frac{\sqrt{1+\left(1-\frac{1}{s^{2}}\right)\left(s v_{w}\right)^{2}}-1}{\left(1-\frac{1}{s^{2}}\right)} \mathrm{d} v_{w}=\frac{s^{2}}{s^{2}-1}\left\{\int_{0}^{1} \sqrt{1+\left(s^{2}-1\right) v_{w}^{2}} \mathrm{~d} v_{w}-1\right\} \\
& \stackrel{6}{=} \frac{s^{2}}{s^{2}-1}\left\{\left[\frac{1}{2} v_{w}\left(\sqrt{1+\left(s^{2}-1\right) v_{w}^{2}}+\frac{\operatorname{arcsinh}\left(\sqrt{s^{2}-1}\right)}{\sqrt{s^{2}-1}}\right)\right]_{0}^{1}-1\right\} \\
& =\frac{s^{2}}{s^{2}-1}\left\{\frac{1}{2} s+\frac{1}{2} \frac{\operatorname{arcsinh}\left(\sqrt{s^{2}-1}\right)}{\sqrt{s^{2}-1}}-1\right\}
\end{aligned}
$$

for the winner, ${ }^{2}$ and

$$
\begin{aligned}
& \bar{\pi}_{\ell}^{*}=\int_{0}^{1} \bar{\pi}_{\ell}^{*}\left(v_{\ell}\right) \mathrm{d} v_{\ell}=\int_{0}^{1} \frac{v_{\ell}^{2}}{1+\sqrt{1-\left(1-\frac{1}{s^{2}}\right) v_{\ell}^{2}}} \frac{1}{s} \mathrm{~d} v_{\ell} \stackrel{3}{=} \int_{0}^{1} \frac{v_{\ell}^{2}\left[1-\sqrt{1-\left(1-\frac{1}{s^{2}}\right) v_{\ell}^{2}}\right]}{1-\left(1-\left(1-\frac{1}{s^{2}}\right) v_{\ell}^{2}\right)} \frac{1}{s} \mathrm{~d} v_{\ell} \\
& =\int_{0}^{1} \frac{1-\sqrt{1-\left(1-\frac{1}{s^{2}}\right) v_{\ell}^{2}}}{\left(1-\frac{1}{s^{2}}\right)} \frac{1}{s} \mathrm{~d} v_{\ell}=\frac{s}{s^{2}-1}\left\{1-\int_{0}^{1} \sqrt{1-\left(1-\frac{1}{s^{2}}\right) v_{\ell}^{2}} \mathrm{~d} v_{\ell}\right\} \\
& \stackrel{6}{=} \frac{s}{s^{2}-1}\left\{1-\left[\frac{1}{2} v_{\ell}\left(\sqrt{1-\left(1-\frac{1}{s^{2}}\right) v_{\ell}^{2}}+\frac{\arcsin \left(\sqrt{1-\frac{1}{s^{2}}}\right)}{\sqrt{1-\frac{1}{s^{2}}}}\right)\right]_{0}^{1}\right\} \\
& =\frac{1}{s^{2}-1}\left\{s-\frac{1}{2}-\frac{1}{2} \frac{s^{2} \arcsin \left(\frac{1}{s} \sqrt{s^{2}-1}\right)}{\sqrt{s^{2}-1}}\right\}
\end{aligned}
$$

for the loser. ${ }^{3}$

The option value effect of winning the first auction $\Delta$ is therefore equal to the difference in expected instantaneous payoffs for the second auction before knowing the second auction valuation between winning and losing. Hence,

$$
\Delta=\bar{\pi}_{w}^{*}-\bar{\pi}_{\ell}^{*}=\frac{s^{2}}{s^{2}-1}\left\{\frac{1}{2} s-1-\frac{1}{s}+\frac{1}{2} \frac{1}{s^{2}}+\frac{1}{2} \frac{\operatorname{arcsinh}\left(\sqrt{s^{2}-1}\right)+\arcsin \left(\frac{1}{s} \sqrt{s^{2}-1}\right)}{\sqrt{s^{2}-1}}\right\}
$$

3. First auction bid functions. The effective first auction valuation has two components: (1) the value of the first object, and (2) the option value of winning. This means that the effective

${ }^{2}$ Here equality 3 is obtained by multiplying the nominator and denominator by $1-\sqrt{1+\left(1-\frac{1}{s^{2}}\right)\left(s v_{w}\right)^{2}}$ and equality 6 is obtained by realizing that $\frac{1}{2} x\left(\sqrt{1+a x^{2}}+\frac{\operatorname{arcsinh}(\sqrt{a})}{\sqrt{a}}\right)$ is the antiderivative of $\sqrt{1+a x^{2}}$.

${ }^{3}$ Here equality 3 is obtained by multiplying the nominator and denominator by $1-\sqrt{1-\left(1-\frac{1}{s^{2}}\right) v_{\ell}^{2}}$ and equality 6 is obtained by realizing that $\frac{1}{2} x\left(\sqrt{1-a x^{2}}+\frac{\arcsin (\sqrt{a})}{\sqrt{a}}\right)$ is the antiderivative of $\sqrt{1-a x^{2}}$. 
valuations are uniformly distributed over the interval $[\Delta, \Delta+1]$. The bid functions stated in the theorem follow directly from here. 